\title{
Al, Machine Learning and sentiment analysis applied to financial markets and consumer markets
}

\author{
Enza Messina ${ }^{1} \cdot$ Christina Erlwein-Sayer $^{2} \cdot$ Gautam Mitra $^{3}$
}

Published online: 7 January 2021

(c) The Author(s), under exclusive licence to Springer-Verlag GmbH, DE part of Springer Nature 2021

The last decades, information technologies based on artificial intelligence (AI) and machine learning (ML) coupled with the increasing availability of data from different sources, are strongly affecting the way business is conducted in financial and retail markets.

The real challenge for businesses in a competitive marketplace is to offer products and services that appeal directly to an individual customer's needs. Information overload makes the use of classical decision models impossible and more sophisticated models are needed to automatically extract important information in order to offer personalized e-services making the decision process easier for customers and enhancing user experience.

Indeed, marketing industries are now using AI and ML for supporting all stages of the customer life cycle, and financial institutions extensively use ML to anticipate financial market developments, predict risky positions and inform approval decisions.

However, while AI and ML techniques have been successfully applied on structured data more complex data structures like networks or even unstructured data are increasingly processed and integrated in ML models.

The selected papers we included in this Special Issue represent some stimulating cross-disciplinary showcases of how AI and ML can be applied to take more informed decision by integrating different sources of data. Complex data structures

Enza Messina

enza.messina@unimib.it

Christina Erlwein-Sayer

Christina.Erlwein-Sayer@htw-berlin.de

Gautam Mitra

gautam@optirisk-systems.com

1 Department of Informatics, Systems and Communication (DISCo), University of MilanoBicocca Viale Sarca 336, 20126 Milan, Italy

2 Department 4, Financial Mathematics, HTW University of Applied Sciences, Campus Wilhelminenhof, Wilhelminenhofstr. 75a, 12459 Berlin, Germany

3 OptiRisk Systems, The Atrium 1 Harefield Rd, Uxbridge UB8 1EX, UK 
are analyzed to take into account interactions among different entities and to understand how their behavior can affect each other.

In particular, the paper by B. Galuzzi, I. Giordani, A. Candelieri, R. Perego and F. Archetti Hyperparameter Optimization for Recommender Systems through Bayesian Optimization and the paper A recommender system for active stock selection by G. De Rossi, J. Kolodziej and G. Brar deal with development and optimization of recommender systems which represent one of the most successful and challenging applications of Machine Learning in online services.

Galuzzi et al. present an interesting methodological approach based on Bayesian Optimization for speeding up the tuning of hyper-parameters when learning a recommendation model. De Rossi and co-authors transfer the idea of recommendation from retail products to stocks selection products for improving portfolio selection by extracting the information available in the data about the holdings of peers, analyzing interactions of the users, and combining it with a traditional market data.

Interaction analysis is the main objective of the papers Risk Attribution and Interconnectedness in the EU via CDS Market Data by R. Giacometti, G. Torri, G. Farina and M. De Giuli, and A missing value approach to social network data: "Dislike" or "Nothing”? by P. Mariani, A. Marletta, M. Mussini, M. Zenga and E. Grammatica.

In Giacometti et al. an analytical networked framework is proposed that by taking into account interactions among institutions in a financial systems integrates systematic and non-systematic components to identify the potential risk transmission channels of distress and risk spillovers.

In Mariani et al. the network under considerations are social networks. In this case the authors propose a method to infer missing information that is however relevant for a correct interpretation of users preferences.

A. Lunde and M. Torkar consider the integrations of different data sources, structured market data and unstructured news, in order to improve price forecasts in their paper Including News Data in Forecasting Macro Economic Performance of China.

A new portfolio allocation method is introduced in the paper Dynamic Portfolio Allocation in Goals-Based Wealth Management by S. Das, D. Ostrov, A. Radhakrishnan, and D. Srivastav. An investment goal is given and the probability to reach this by the investor is maximized, considering amongst other factors possible shifts in retirement planning and withdrawals. Information is processed, the optimal asset allocation adapted and the desired wealth value achieved.

Acknowledgements We are grateful to Profs. Rüdiger Schultz and Stein-Erik Fleten, the Editors-in-Chief of the Journal Computational Management Science, to enable the publication of this Special Issue on AI, Machine Learning and Sentiment Analysis.

Publisher's Note Springer Nature remains neutral with regard to jurisdictional claims in published maps and institutional affiliations. 